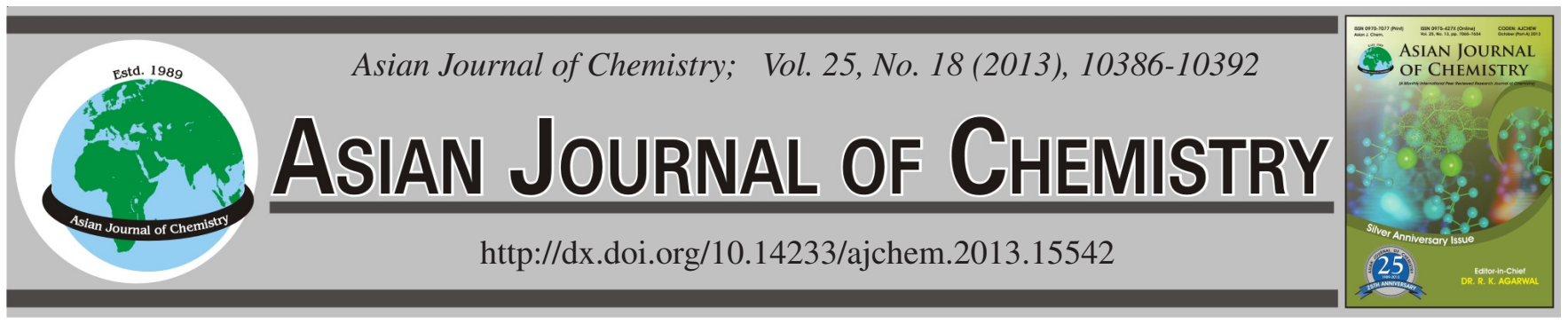

\title{
Thermal and Spectroscopic Studies of Transition Metal Complexes with Dihydrobis(2-Mercaptobenzothiazolyl)borate
}

\author{
Naushad Ahmad ${ }^{1, *}$, Manawwer Alam $^{1}$, Parveen Kumar $^{2}$, Athar Adil Hashmi $^{2}$ and Rizwan Wahab ${ }^{3}$
}

\begin{abstract}
${ }^{1}$ Department of Chemistry, College of Science King Saud University, Riyadh 11451, Kingdom of Saudi Arabia
${ }^{2}$ Department of Chemistry, Jamia Millia Islamia, New Delhi-110 025, India

${ }^{3}$ Department of Zoology, College of Science, King Saud University, Riyadh 11451, Kingdom of Saudi Arabia
\end{abstract}

*Corresponding author: E-mail: naushaddrnaima@gmail.com

\begin{abstract}
The complexing behaviour of dihydrobis(2-mercaptobenzothiazolyl)borate towards the transition metal ions namely, Co(II), Ni(II) and $\mathrm{Cu}(\mathrm{II})$ have been examined by elemental analysis, magnetic susceptibility, thermal, conductivity and spectral studies viz. FT-IR, NMR, UV-VIS and ESI-MS. Spectroscopic results support a square planar geometry in Cu(II) complex, while an octahedral geometry is suggested in case of $\mathrm{Co}(\mathrm{II})$ and $\mathrm{Ni}(\mathrm{II})$ complexes. Thermal behaviour and kinetics of all compounds are investigated by thermogravimetric analysis. The TGA profile of borate anion and $\mathrm{Cu}$ (II) complex shows a single stage unlike that of two stage decomposition plot of the Co(II) and $\mathrm{Ni}(\mathrm{II})$ complexes. The evaluation of kinetic parameters (E, ln $\mathrm{A}, \Delta \mathrm{H}, \Delta \mathrm{S}$ and $\Delta \mathrm{G}$ ) of all thermal decomposition stages have been evaluated by graphical method using the equation of Coats-Redfern equation. The activation energy of $\mathrm{Co}(\mathrm{II}), \mathrm{Ni}(\mathrm{II})$ and $\mathrm{Cu}(\mathrm{II})$ complexes expected to increase in relation with decreasing in their radius. The molar conductance of these complexes shows a non-electrolyte behaviour.
\end{abstract}

Key Words: Dihydrobis(2-mercaptobenzothiazolyl)borate, Metal complexes, Thermal analysis, Energy of activation.

\section{INTRODUCTION}

Nitrogen containing borate, such as triazolyl $\mathbf{l}^{1}$, pyrazoly ${ }^{2}$ indazolylm ${ }^{3}$, poly(indazolyl) and poly(2-mercaptothiazolyl) borate ${ }^{4}$ occupy a unique place in coordination chemistry because having outstanding biological and thermal properties towards with transition metals. This family of $\mathrm{N}$-donors is not able only to control the steric and electronic environment about a metal center by modification of the pyrazolyl substituents but also to give multimetallic transition metal complexes maintaining the metal centers in close proximity. This is a very interesting feature because of the potential role of this kind of derivative in multimetal-centered catalysis in both biological and industrial thermal reactions. Tripodal borate $\mathrm{S}, \mathrm{N}$ ligands such as hydrotris(thioxoimidazolyl)borate and hydrotris(2mercaptothiazolyl)borate ${ }^{5}$ are softer than the pyrazolyl analogues and as such are more useful to be used as supporting ligands with transition metals. Although these ligands are closely related to the bis(pyrazolyl)borate ligands, they exhibit a number of characteristics that set them apart. The combination of boron, sulfur and nitrogen containing ligands led to work in coordination chemistry of transition metal complexes.

In present work, we reports the synthesis, spectral and thermogravimetric (TGA) studies of dihydrobis(2-mercapto- benzothiazolyl)borate and its transition metal complexes (Scheme-I). The thermal degradation kinetic parameters such as energy of activation (E) and the pre-exponential factor ( $\ln \mathrm{A})$ by employing Coats-Redfern method and thermodynamic parameters like entropy $(\Delta \mathrm{S})$, enthalpy $(\Delta \mathrm{H})$ and activation energy $(\Delta \mathrm{G})$ for each step of degradation have been evaluated.

\section{EXPERIMENTAL}

All chemicals were used of Analytical grade and purchased from Sigma Aldrich. Elemental analyses were performed on a Perkin-Elmer 2400 Series II, CHNS/O Analyzer. The metal contents were determined by EDTA titration after decomposition with mixture of $\mathrm{HCl}$ and $\mathrm{HClO}_{4}$. The molar conductances of the complexes were measured using a Consort type C-533 conductivity instrument at room temperature in $10^{-3} \mathrm{M} \mathrm{DMSO}$ solvent. FT-IR spectra were recorded on Perkin-Elmer system 2000 FT-IR spectrophotometer. ${ }^{1} \mathrm{H}$ and ${ }^{13} \mathrm{C}$ NMR spectra were recorded on a Bruker Avance DPX200 spectrometer operating using tetramethylsilane(TMS) as an internal standard. ${ }^{11} \mathrm{~B}$ NMR spectrum was recorded on a Bruker Avance DPX400 spectrometer using $\mathrm{BF}_{3}$. $\mathrm{Et}_{2} \mathrm{O}$ as an internal reference. Electronic spectra were recorded on a Perkin-Elmer Lambda-25 UV-Vis spectrometer using water as solvent. The magnetic susceptibility measurement at room temperature was carried 


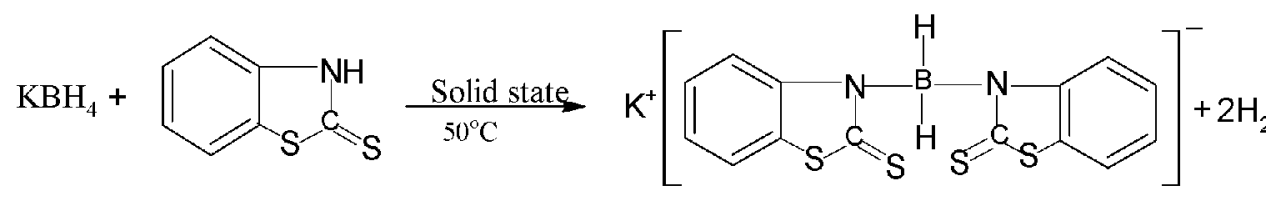

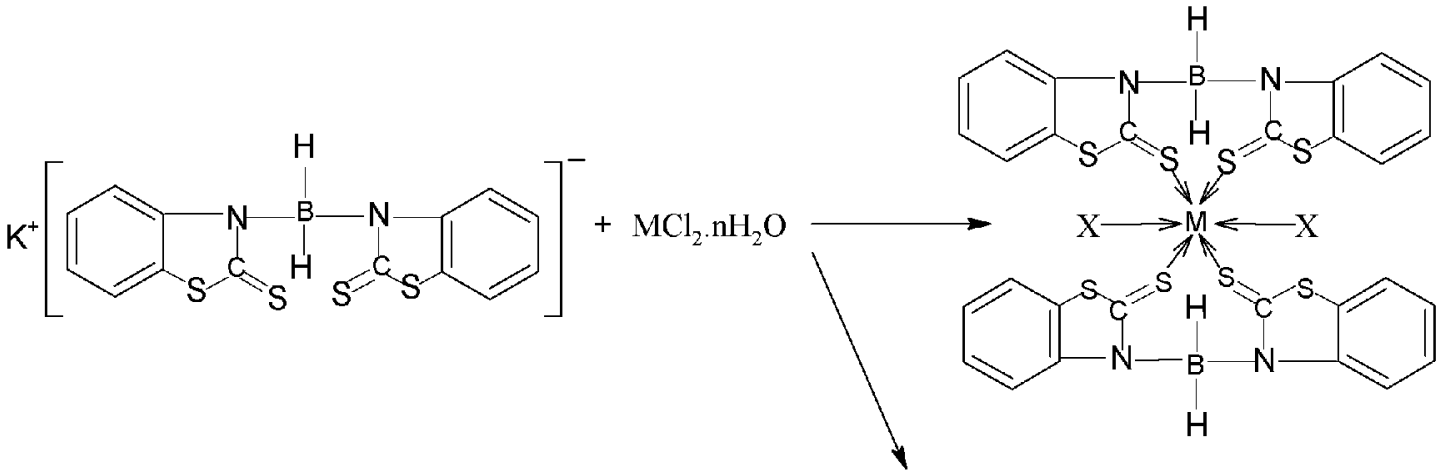
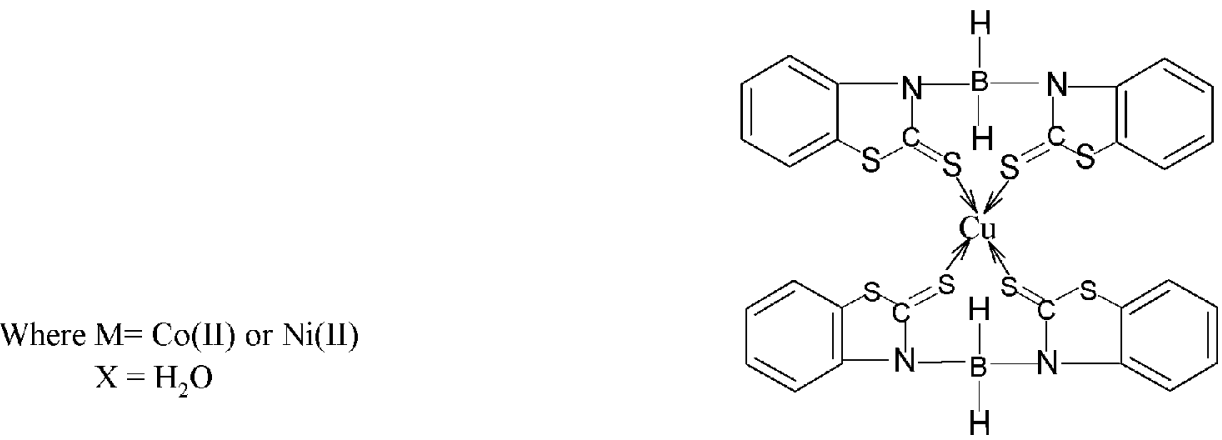

Scheme-I

out by Gouy's method using mercury(II) tetraisothiocyanatocabaltate(II), as reference. Diamagnetic susceptibility corrections for ligand susceptibility were made using Pascal's constants and effective magnetic moments were calculated by the equation $\mu_{\mathrm{eff}}=2.828\left(\chi_{\mathrm{M}} \mathrm{T}\right)^{1 / 2}$, where $\chi_{\mathrm{M}}$ is the molar magnetic susceptibility corrected for diamagnetisms of the constituting atoms. The thermal analysis was performed using TA instruments, SDT Q-600. All TGA experiments were conducted in a helium environment with a purge flow rate of $100 \mathrm{~mL} \mathrm{~min}^{-1}$. For each experiment, 8 to $10 \mathrm{mg}$ of the sample was loaded into alumina crucibles $\left(\mathrm{Al}_{2} \mathrm{O}_{3}\right)$ in the heating zone of the TGA. An empty pan was used as reference and samples were runs from room temperature to $800^{\circ} \mathrm{C}$ at heating rates $20^{\circ} \mathrm{C} \mathrm{min}{ }^{-1}$. Positive and negative mode ESI mass spectra were recorded on a MICRO MASS QUATTRO (II), triplet quadruple mass spectrometer using $\mathrm{CH}_{3} \mathrm{OH}$ as solvent. The sample was introduced into the ESI source through a syringe pump at the rate of $5 \mu \mathrm{L}$ $\min ^{-1}$. The ESI capillary was set at $3.5 \mathrm{kV}$ and voltage $40 \mathrm{~V}$.

Synthesis of potassium dihydrobis(2-mercaptobenzothiazolyl)borate ligand (KL): Fine powder of 2-mercaptobenzothiazole $(10.03 \mathrm{~g}, 60 \mathrm{mmol})$ and potassium borohydride $(1.08 \mathrm{~g}, 20 \mathrm{mmol})$ were placed in a $250 \mathrm{~mL}$ round bottom flask connected with a gas collecting device through a condenser containing magnetic stirring bar. This assembly placed in an oil bath and mixture was heated at $50{ }^{\circ} \mathrm{C}$ until $530.05 \mathrm{~mL}$ (20 $\mathrm{mmol}$ ) hydrogen gas had been evolved. It was allowed to cool at room temperature and $20 \mathrm{~mL}$ methanol was added and mixture was stirred for $0.5 \mathrm{~h}$. Ligand separated and washed several times with hexane, THF and diethyl ether. The solid residue was dried in vacuum desiccator to constant weight under reduced pressure to leave the desired compound as a yellowish power. It was re-crystallized from methanol. Yield (\%): 70.39; m.p. $275^{\circ} \mathrm{C}$; MS (ESI+): $384[\mathrm{M}]^{+}, 318$ $\left[\mathrm{KBC}_{14} \mathrm{H}_{8} \mathrm{~N}_{2} \mathrm{~S}_{4}\right], 288\left[\mathrm{BC}_{8} \mathrm{H}_{8} \mathrm{ON}_{2} \mathrm{~S}_{4}\right]$; Elemental analysis $(\%)$ found (calcd. for $\mathrm{KBC}_{14} \mathrm{H}_{10} \mathrm{~N}_{2} \mathrm{~S}_{4}$ ): C 43.68 (43.74), H 2.59 (2.61), N 7.26 (7.29), S 33.34 (33.37); IR (KBr, $\left.v_{\max }, \mathrm{cm}^{-1}\right)$ : 1425 (B-N), 2327 (B-H), $990(\mathrm{C}=\mathrm{S})$.

Synthesis of metal(II) complexes: A methanolic solution $(15 \mathrm{~mL})$ of corresponding metal salt $(1 \mathrm{mmol})$ was added to methanolic solution ( $15 \mathrm{~mL}$ ) of ligand $(0.769 \mathrm{~g}, 2 \mathrm{mmol})$. The resulting mixture was heated under reflux with stirring for 4-5 h. On cooling coloured complex precipitated out, which was filtered washed with several times with cold methanol and diethyl ether and dried in vacuo over anhydrous $\mathrm{CaCl}_{2}$. The compound was recovered in solid state and was re-crystallized from methanol. Yields, elemental analysis results and characteristic FT-IR bands are given in Tables 1 and 2.

\section{RESULTS AND DISCUSSION}

Ligand is hygroscopic yellow solids, soluble in polar organic solvents and water and relatively resistant towards aerobic oxidation and hydrolysis. The ligand is expected to act as monoanionic bidentate ligand towards the divalent metal ions. All the isolated complexes were insoluble in most common organic solvent but soluble in polar solvents with meting point above $300{ }^{\circ} \mathrm{C}$. The results of the elemental analyses (Table-1) and spectral studies are consistent with proposed composition of the ligand and its corresponding metal complexes. The molar conductance measurements at room temperature show a nonelectrolytic nature of metal complexes ${ }^{6}$. Molecules of water 
TABLE-1

ANALYTICAL AND PHYSICAL DATA OF THE BORATE LIGAND AND ITS Co(II), Ni(II) AND Cu(II) METAL COMPLEXES

\begin{tabular}{|c|c|c|c|c|c|c|c|c|c|}
\hline \multirow{2}{*}{ Compounds } & \multirow{2}{*}{ f.w. } & \multirow{2}{*}{$\begin{array}{l}\text { Molar conductance } \\
\left(\Omega^{-1} \mathrm{~cm}^{2} \mathrm{~mol}^{-1}\right)\end{array}$} & \multirow{2}{*}{$\begin{array}{l}\text { Yield } \\
(\%)\end{array}$} & \multirow{2}{*}{ Colour } & \multicolumn{5}{|c|}{ Elemental analysis ${ }^{\mathrm{a}}$} \\
\hline & & & & & $\mathrm{C}$ & $\mathrm{H}$ & $\mathrm{N}$ & $\mathrm{S}$ & M \\
\hline $\begin{array}{c}\text { Ligand, } \\
\text { KLKBC }_{14} \mathrm{H}_{10} \mathrm{~N}_{2} \mathrm{~S}_{4}\end{array}$ & 384.5 & - & 79.39 & Yellow & $\begin{array}{c}43.68 \\
(43.74)\end{array}$ & $\begin{array}{l}2.59 \\
(2.61)\end{array}$ & $\begin{array}{c}7.26 \\
(7.28)\end{array}$ & $\begin{array}{c}32.34 \\
(33.37)\end{array}$ & - \\
\hline $\begin{array}{c}{\left[\mathrm{Co}(\mathrm{L})_{2}\left(\mathrm{H}_{2} \mathrm{O}\right)_{2}\right]} \\
\mathrm{B}_{2} \mathrm{C}_{28} \mathrm{H}_{24} \mathrm{~N}_{4} \mathrm{~S}_{8} \mathrm{O}_{2} \mathrm{Co}\end{array}$ & 785.5 & 15.29 & 73.05 & Blue & $\begin{array}{c}42.72 \\
(42.81)\end{array}$ & $\begin{array}{l}3.05 \\
(3.08)\end{array}$ & $\begin{array}{l}7.09 \\
(7.13)\end{array}$ & $\begin{array}{c}32.62 \\
(32.65)\end{array}$ & $\begin{array}{l}7.48 \\
(7.50)\end{array}$ \\
\hline $\begin{array}{c}{\left[\mathrm{Ni}(\mathrm{L})_{2}\left(\mathrm{H}_{2} \mathrm{O}\right)_{2}\right]} \\
\mathrm{B}_{2} \mathrm{C}_{28} \mathrm{H}_{24} \mathrm{~N}_{4} \mathrm{~S}_{8} \mathrm{O}_{2} \mathrm{Ni}\end{array}$ & 785.3 & 12.09 & 70.12 & Green & $\begin{array}{c}42.79 \\
(42.82)\end{array}$ & $\begin{array}{c}3.06 \\
(3.08)\end{array}$ & $\begin{array}{c}7.09 \\
(7.13)\end{array}$ & $\begin{array}{c}33.61 \\
(33.66)\end{array}$ & $\begin{array}{c}7.41 \\
(7.47)\end{array}$ \\
\hline $\begin{array}{c}{\left[\mathrm{Cu}(\mathrm{L})_{2}\right]} \\
\mathrm{B}_{2} \mathrm{C}_{28} \mathrm{H}_{20} \mathrm{~N}_{4} \mathrm{~S}_{8} \mathrm{Cu}\end{array}$ & 754.2 & 16.49 & 68.09 & Brown & $\begin{array}{c}45.29 \\
(45.31)\end{array}$ & $\begin{array}{l}2.63 \\
(2.67)\end{array}$ & $\begin{array}{c}7.42 \\
(7.43)\end{array}$ & $\begin{array}{c}34.13 \\
(34.01)\end{array}$ & $\begin{array}{l}8.41 \\
(8.43)\end{array}$ \\
\hline
\end{tabular}

${ }^{39}$ Observed (calculated) values. ${ }^{40} \mathrm{~L}=\mathrm{BC}_{14} \mathrm{H}_{10} \mathrm{~N}_{2} \mathrm{~S}_{4}$.

TABLE-2

IR SPECTRAL DATA $\left(\mathrm{cm}^{-1}\right)$ OF THE BORATE LIGAND AND ITS METAL COMPLEXES

\begin{tabular}{lcccccc}
\hline \multicolumn{1}{c}{ Compound } & $v(\mathrm{~B}-\mathrm{N})$ & $v(\mathrm{~B}-\mathrm{H})$ & $v(\mathrm{C}=\mathrm{S})$ & $v(\mathrm{C}-\mathrm{H})$ & $v(\mathrm{M}-\mathrm{S})$ & - \\
\hline Ligand, $\mathrm{KL}$ & 1425 & 2327 & 990 & 2926 & - & \\
{$\left[\mathrm{Co}(\mathrm{L})_{2}\left(\mathrm{H}_{2} \mathrm{O}\right)_{2}\right]$} & 1429 & 2343 & 1023 & 2939 & 343 & 551 \\
{$\left[\mathrm{Ni}(\mathrm{L})_{2}\left(\mathrm{H}_{2} \mathrm{O}\right)_{2}\right]$} & 1431 & 2354 & 1029 & 2921 & 354 & 582 \\
{$\left[\mathrm{Cu}(\mathrm{L})_{2}\right]$} & 1434 & 2339 & 1036 & 2928 & 364 & - \\
\hline
\end{tabular}

in $\mathrm{Co}(\mathrm{II})$ and $\mathrm{Ni}(\mathrm{II})$ complexes are supported by elemental analysis and spectral data. The ligand and its metal complexes were formed according to the Scheme-I.

Infrared spectral: A stretching vibration of medium intensity at $1425 \mathrm{~cm}^{-1}$ due to the B-N, strongly favours formation of ligand ${ }^{7}$. The ligand showed a strong B-H stretch ${ }^{8}$ at $2327 \mathrm{~cm}^{-1}$ and medium vibration of $\mathrm{C}=\mathrm{S}$ group ${ }^{9}$ at $990 \mathrm{~cm}^{-1}$ confirmed attachment of 2-mercaptobenzothiazoline moiety with boron through sulfur atom (Table-2). In addition, several other bands in the broad region of $1563-700 \mathrm{~cm}^{-1}$ can be attributed to vibrations involving interaction between $\mathrm{C}=\mathrm{S}$ and C-N. The infrared spectra of the metal complexes confirmed that after coordination to transition metal(II) ions, all the above stretching bands of ligand were insignificantly shifted except the $\mathrm{C}=\mathrm{S}$ peak which is significantly shifted to higher wavenumber confirmed the formation of a coordinate bond between $\mathrm{C}=\mathrm{S}$ and metal(II) ions. These shifts are consistent with a decrease in the order of the $\mathrm{C}=\mathrm{S}$ bonds upon coordination and a shift of electron density, producing a partial double-bond character in the $\mathrm{C}-\mathrm{N}$ bond. The low frequency vibrations due to $\mathrm{M}-\mathrm{O}$ and $\mathrm{M}-\mathrm{S}$ stretching provide direct evidence for the complexation. Presence of stretching vibration at 551 and $582 \mathrm{~cm}^{-1}$ in $\mathrm{Co}$ (II) and $\mathrm{Ni}$ (II) complexes, respectively shows the linkage between $\mathrm{M}-\mathrm{O}$ bonds ${ }^{15}$. The presence of coordinated water molecules in the metal complexes was further confirmed by appearance of bands in the region $1600-1540 \mathrm{~cm}^{-1}$ for deformation and in $870-840 \mathrm{~cm}^{-1}$ for rocking modes of coordinated water ${ }^{11,12}$. Another signal in the region $364-343 \mathrm{~cm}^{-1}$ shows the presence of M-S bond in all metal complexes ${ }^{13}$.
NMR spectra: In ${ }^{1} \mathrm{H}$ NMR spectrum of the ligand, the absence of N-H or S-H proton signal 12-15 ppm and presence of a broad singlet of B-H protons at 4.52 ppm confirmed formation of the ligand ${ }^{14}$. The two doublets betweent 7.6-8.2 ppm show the aromatic ring protons of 2-mercaptobenza- thiazoline ${ }^{15}$. In ${ }^{13} \mathrm{C}$ NMR spectrum of ligand, the signals of $>\mathrm{C}-\mathrm{N}$ and $>\mathrm{C}-\mathrm{S}$ appear at 155 and $135 \mathrm{ppm}$, respectively while other benzene ring carbons of 2-mercaptobenzathiazoline are at 122-131 ppm. The chemical shift at $190.83 \mathrm{ppm}$ indicates the presence of $\mathrm{C}=\mathrm{S}$ group ${ }^{16} .{ }^{11} \mathrm{~B} \mathrm{NMR}$ has show a signal at $4.21 \mathrm{ppm}$ for the $\mathrm{B}-\mathrm{H}^{4}$. FT IR spectra also confirmed the characteristics band at $2317 \mathrm{~cm}^{-1}$ for B-H.

Electronic spectra and magnetic moments: The electronic spectra of metal complexes were measured and their spectral data are listed in the Table-3, which include the absorption regions, band assignments, ligand field parameters and the proposed geometry of the complexes. The electronic spectrum of $\mathrm{Cu}$ (II) complex (Fig. 1a) showed two characteristic bands at 14010 and $19596 \mathrm{~cm}^{-1}$. These bands may be assigned to ${ }^{2} \mathrm{~B}_{1 \mathrm{~g}} \rightarrow{ }^{2} \mathrm{~A}_{1 \mathrm{~g}}$ and ${ }^{2} \mathrm{~B}_{1 \mathrm{~g}} \rightarrow 2 \mathrm{E}_{\mathrm{g}}$ transitions, respectively ${ }^{17}$, which indicate square-planar geometry. In the present study the magnetic moment value of $\mathrm{Cu}$ (II) complex was found to be 1.79 $\mathrm{BM}$, which is in accordance with square planar geometry ${ }^{18}$.

The Co(II) complex had a magnetic moment of 4.83 BM, corresponding to four unpaired electrons. This value was consistent with the high spin octahedral geometry. This higher $\mu_{\text {eff }}$ value of the $\mathrm{Co}$ (II) complex was attributed to the orbital contribution $^{19}$. Electronic spectrum of the Co(II) complex exhibits absorptions in the region 9135,16285 and 23041 which may

\begin{tabular}{|c|c|c|c|c|c|c|c|}
\hline \multicolumn{8}{|c|}{$\begin{array}{l}\text { TABLE-3 } \\
\text { MAGNETIC MOMENT AND ELECTRONIC SPECTRAL DATA OF METAL COMPLEXES }\end{array}$} \\
\hline Compounds & $\begin{array}{c}\text { Magnetic } \\
\text { moment } \\
\left(\mu_{\text {eff }}\right)\end{array}$ & Frequency $\left(\mathrm{cm}^{-1}\right)$ & Assignments & $\begin{array}{c}\Delta_{\mathrm{o}} \\
\left(\mathrm{cm}^{-1}\right)\end{array}$ & $\begin{array}{c}\mathrm{B} \\
\left(\mathrm{cm}^{-1}\right)\end{array}$ & $\beta$ & Geometry \\
\hline$\left[\mathrm{Co}(\mathrm{L})_{2}\left(\mathrm{H}_{2} \mathrm{O}\right)_{2}\right]$ & 4.83 & $9135,16285,23041$ & $\begin{aligned}{ }^{4} \mathrm{~T}_{1 \mathrm{~g}(\mathrm{~F})} & \rightarrow{ }^{4} \mathrm{~T}_{2 \mathrm{~g}(\mathrm{~F})},{ }^{4} \mathrm{~T}_{1 \mathrm{~g}(\mathrm{~F})} \rightarrow{ }^{4} \mathrm{~A}_{2 \mathrm{~g}(\mathrm{~F})}, \\
{ }^{4} \mathrm{~T}_{1 \mathrm{~g}(\mathrm{~F})} & \rightarrow{ }^{4} \mathrm{~T}_{1 \mathrm{~g}(\mathrm{P})}\end{aligned}$ & 10375 & 415 & 0.370 & Octahedral \\
\hline$\left[\mathrm{Ni}(\mathrm{L})_{2}\left(\mathrm{H}_{2} \mathrm{O}\right)_{2}\right.$ & 2.90 & $9810,15384,23520$ & $\begin{array}{c}{ }^{3} \mathrm{~A}_{2 \mathrm{~g}(\mathrm{~F})} \rightarrow{ }^{3} \mathrm{~T}_{2 \mathrm{~g}(\mathrm{~F})},{ }^{3} \mathrm{~A}_{2 \mathrm{~g}(\mathrm{~F})} \rightarrow{ }^{3} \mathrm{~T}_{1 \mathrm{~g}(\mathrm{~F})} \\
{ }^{3} \mathrm{~A}_{2 \mathrm{~g}(\mathrm{~F})} \rightarrow{ }^{3} \mathrm{~T}_{1 \mathrm{~g}(\mathrm{P})}\end{array}$ & 11118 & 654 & 0.605 & Octahedral \\
\hline$\left[\mathrm{Cu}(\mathrm{L})_{2}\right]$ & 1.79 & 14010,19596 & $\mathrm{~B}_{\lg (\mathrm{F})} \rightarrow^{2} \mathrm{~A}_{\lg (\mathrm{F})}$, charge transfer & & & & Square planar \\
\hline
\end{tabular}



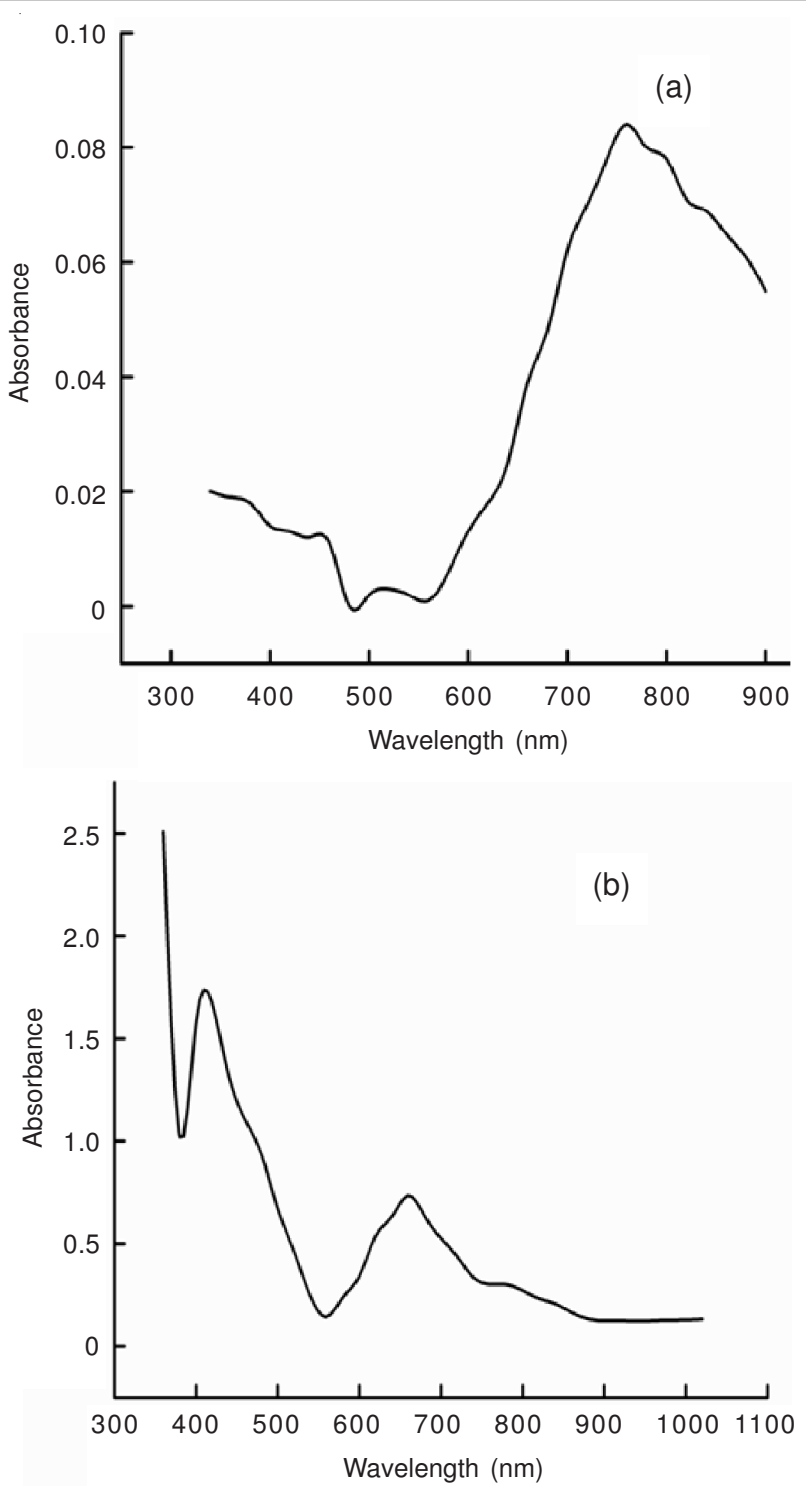

Fig. 1. Electronic spectra of $\mathrm{Cu}(\mathrm{II})$ and $\mathrm{Ni}(\mathrm{II})$ complexes

be assigned to the ${ }^{4} \mathrm{~T}_{1 \mathrm{~g}(\mathrm{~F})} \rightarrow{ }^{4} \mathrm{~T}_{2 \mathrm{~g}(\mathrm{~F})(\mathrm{vl})},{ }^{4} \mathrm{~T}_{1 \mathrm{~g}(\mathrm{~F})} \rightarrow{ }^{4} \mathrm{~A}_{2 \mathrm{~g}(\mathrm{~F})(\mathrm{v} 2)}$ and ${ }^{4} \mathrm{~T}_{\lg (\mathrm{F})} \rightarrow{ }^{4} \mathrm{~T}_{\mathrm{lg}(\mathrm{P})(\mathrm{v} 3)}$, respectively ${ }^{20}$ suggesting an octahedral environment around the $\mathrm{Co}$ (II) ion in the complex. On the basis of these assignments the ligand field parameters calculated for $\mathrm{Co}(\mathrm{II})$ complex are $\Delta_{\mathrm{o}}=10375 \mathrm{~cm}^{-1} ; \mathrm{B}=415 ; \beta=$ 0.370. Similarly Ni(II) complex (Fig. 1 b) exhibits absorption bands in the region around 9810,15384 and $23520 \mathrm{~cm}^{-1}$. These bands may be assigned to the spin allowed transition: ${ }^{3} \mathrm{~A}_{2 \mathrm{~g}(\mathrm{~F})} \rightarrow{ }^{3} \mathrm{~T}_{2 \mathrm{~g}(\mathrm{~F})(\mathrm{vl})},{ }^{3} \mathrm{~A}_{2 \mathrm{~g}(\mathrm{~F})} \rightarrow{ }^{3} \mathrm{~T}_{1 \mathrm{~g}(\mathrm{~F})(\mathrm{v} 2)}$ and ${ }^{3} \mathrm{~A}_{2 \mathrm{~g}(\mathrm{~F})} \rightarrow{ }^{3} \mathrm{~T}_{1 \mathrm{~g}(\mathrm{P})(\mathrm{v}) \text {, }}$ respectively which display the characteristic pattern for octahedral $\mathrm{Ni}$ (II) complex ${ }^{21}$. On the basis of these assignments the ligand field parameters calculated for $\mathrm{Ni}(\mathrm{II})$ complex are $\Delta_{\mathrm{o}}=11118 \mathrm{~cm}^{-1} ; \mathrm{B}=654 ; \beta=0.605$. Thus the reduction of the Racah parameter from the free ion values and values of $\beta$ indicate covalent character of the metal ligand ' $\sigma$ ' bond. The octahedral $\mathrm{Ni}$ (II) complex was expected to be paramagnetic owing to the two unpaired $d$-electrons and the experimental magnetic moment was found to be $2.90 \mathrm{BM}^{22}$. The above discussion is strongly indicates octahedral geometry around the central metal ion in the $\mathrm{Co}(\mathrm{II})$ and $\mathrm{Ni}(\mathrm{II})$ complexes, requiring occupation of two coordination by $\mathrm{H}_{2} \mathrm{O}$.
Thermogravimetric analysis: Thermogravimetric and differential DTG were carried out for ligand and its complexes under helium flow. The TGA exhibited one and two-stage decomposition patterns. Typical TGA and DTG curves are presented in Fig. 2 and the temperature ranges with percentage weight losses of the decomposition process are given in Table-4, together with the temperature of greatest rate of decomposition $\left(\mathrm{DTG}_{\max }\right)$. Ligand was stable up to $250^{\circ} \mathrm{C}$, leaving more than $5 \%$ residue of $\mathrm{B}-\mathrm{N}$ moiety. The first stage of degradation at 239.83 and $288.95^{\circ} \mathrm{C}$ in $\mathrm{Co}(\mathrm{II})$ and $\mathrm{Ni}$ (II) complexes which is accompanied by a weight loss of 52.56 and $34.74 \%$, respectively corresponding to the loss chemically bound water (coordinated water) and metals with organic parts. The second decomposition stage occurs at a maxima temperature of 482.04 and $643.80^{\circ} \mathrm{C}$ for $\mathrm{Co}(\mathrm{II})$ and $\mathrm{Ni}(\mathrm{II})$ complexes, respectively. The weight loss associated with this step is $36.69 \%$ for $\mathrm{Co}$ (II) and $32.55 \%$ for $\mathrm{Ni}(\mathrm{II})$ due to the loss of the organic compounds. The TGA of $\mathrm{Cu}$ (II) complex is interestingly different from that of the other two complexes showing no sign of coordinated water molecule in the complex, which confirms the anhydrous nature of the $\mathrm{Cu}$ (II) complex. The complex is stable up to $205^{\circ} \mathrm{C}$ and decomposition begins beyond this temperature. The complex shows a major step of weight loss between 220$400{ }^{\circ} \mathrm{C}$ corresponds to the loss of organic moiety followed by $\mathrm{CO}_{2}$ and leaves bluish black $\mathrm{CuS}$ as residue.

Thermal kinetics investigation: Non-isothermal methods have been extensively used for the evaluation of kinetic parameters of solid-state decomposition reactions by analysis of TGA curves. The rate of a decomposition process can be described as the product of two separate functions of temperature and conversion $^{23}$, using

$$
v=\left(\frac{\mathrm{d} \alpha}{\mathrm{dt}}\right)=\mathrm{k}(\mathrm{T}) \mathrm{f}(\alpha)
$$

where $\alpha$ is the fraction decomposed at time $t, k(T)$ the temperature dependent function and $f(\alpha)$ is the conversion function dependent on the mechanism of decomposition. It has been established that the temperature dependent function $\mathrm{k}(\mathrm{T})$ is of the Arrhenius type and can be considered as the rate constant $\mathrm{k}$ :

$$
\mathrm{k}(\mathrm{T})=\mathrm{A} \exp \left(-\frac{\mathrm{E}}{\mathrm{RT}}\right)
$$

where $\mathrm{A}$ is the frequency factor, is a measure of the probability that a molecule having activation energy $\mathrm{E}$ will participate in a reaction. $\mathrm{R}$ is gas constant $\left(8.314 \mathrm{~J} \mathrm{~mol}^{-1} \mathrm{~K}^{-1}\right)$. In non-isothermal conditions with a linear heating rate of $\beta=\mathrm{dT} / \mathrm{dt}$, eqn. 2 can be written as

$$
\left(\frac{\mathrm{d} \alpha}{\mathrm{dt}}\right)=\left(\frac{\mathrm{A}}{\beta}\right) \mathrm{f}(\alpha) \exp \left(-\frac{\mathrm{E}}{\mathrm{RT}}\right)
$$

On integration and approximation, this equation can be obtained in the following form:

$$
g(\alpha)=-\frac{E}{R T}+\ln \left[\frac{\mathrm{AR}}{\beta E}\right]
$$

where $g(\alpha)$ is a function of $\alpha$ dependent on the mechanism of the reaction. The integral on the right-hand side is known as temperature integral and has no closed for solution. So several techniques have been used for the evaluation of temperature 

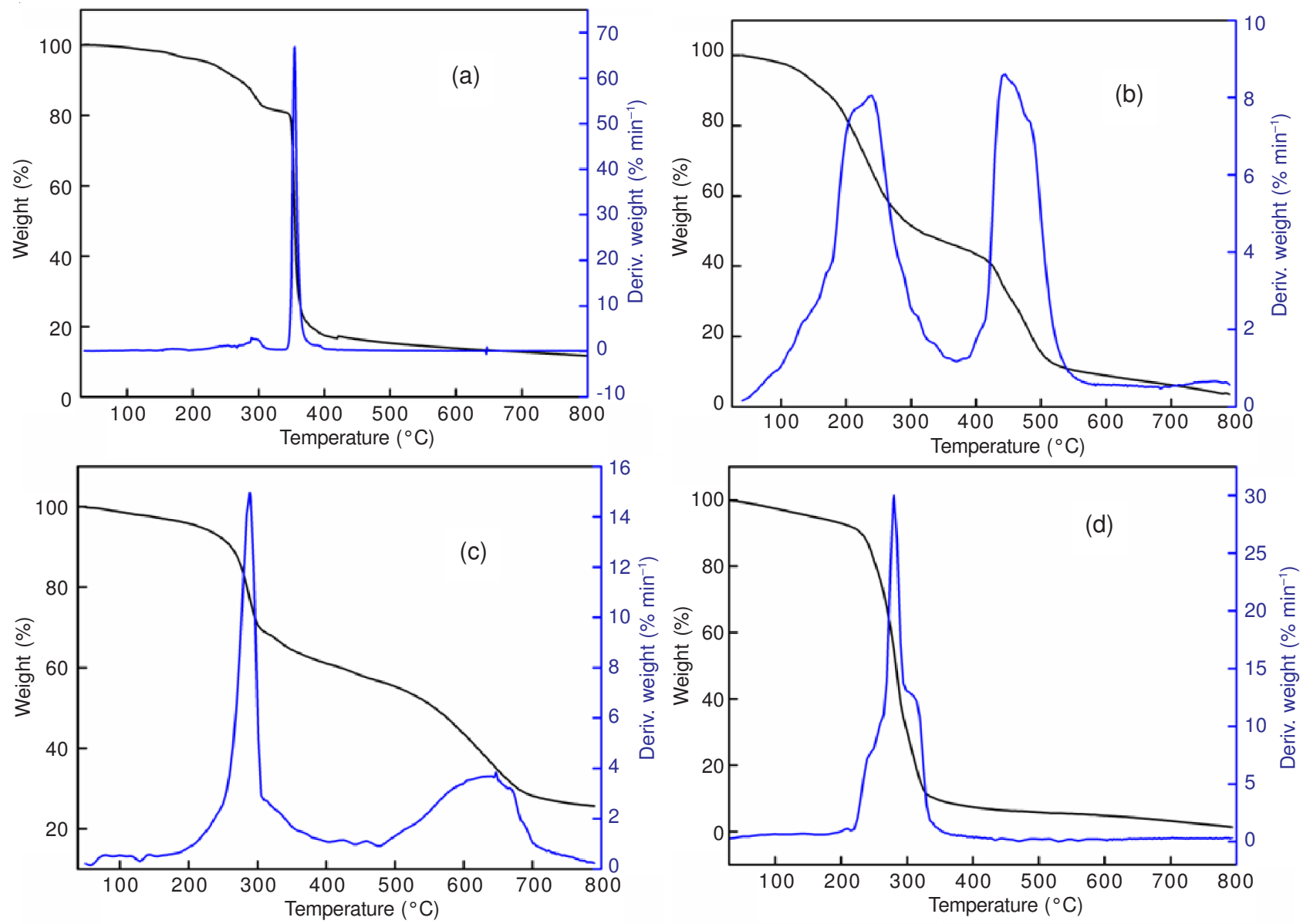

Fig. 2. TG-DTG curves of: (a) KL (b) $\mathrm{Co}$ (II) (c) $\mathrm{Ni}$ (II) and (d) $\mathrm{Cu}$ (II) complexes

\begin{tabular}{cccccc}
\multicolumn{5}{c}{ TABLE-4 } \\
& \multicolumn{5}{c}{ THERMO ANALYTICAL RESULTS OF LIGAND AND ITS METAL COMPLEXES } \\
\hline Compound & Stage & Temperature range $\left({ }^{\circ} \mathrm{C}\right)$ & DTG $_{\max }$ & Weight loss $(\%)$ & Residue \\
\hline Ligand, $\mathrm{KL}$ & I & $250-400$ & 355.78 & 74.87 & 5.81 \\
{$\left[\mathrm{Co}(\mathrm{L})_{2}\left(\mathrm{H}_{2} \mathrm{O}\right)_{2}\right]$} & I, II & $50-350,350-550$ & $239.83,482.04$ & $52.56,36.69$ & 6.87 \\
{$\left[\mathrm{Ni}(\mathrm{L})_{2}\left(\mathrm{H}_{2} \mathrm{O}\right)_{2}\right]$} & I, II & $200-400,400-700$ & $288.95,643.80$ & $34.74,32.55$ & 2.83 \\
{$\left[\mathrm{Cu}(\mathrm{L})_{2}\right]$} & I & $220-400$ & 280.48 & 80.01 & 12.65 \\
\hline
\end{tabular}

integral. In the present investigation integral method of Coats-Redfern ${ }^{24}$ has been used to evaluate kinetic parameters because it is superior to other methods and shows the best linearity of the data.

The Coats-Redfern eqn. 5 can be represented as

$$
g(\alpha)=\int_{0}^{\alpha} \frac{d(\alpha)}{f(\alpha)}=\left(\frac{A}{\beta}\right) \int_{T_{0}}^{T} \exp \left(-\frac{E}{R T}\right) d T
$$

where $T_{0}$ is the temperature at the onset of the reaction. No conversion occurs before $\mathrm{T}_{0}$; therefore, $\mathrm{T}_{0}$ can bet set equal to zero for convenience. This equation on integration gives

$$
\ln -\frac{\ln (1-\alpha)}{\mathrm{T}^{2}}=-\frac{\mathrm{E}}{\mathrm{RT}}+\ln \frac{\mathrm{AR}}{\beta \mathrm{E}}
$$

A plot of left-hand side against 1000/T was drawn. E (kJ $\left.\mathrm{mol}^{-1}\right)$ and calculated from the slop and $\mathrm{A}\left(\mathrm{s}^{-1}\right)$ from the intercept value. The other kinetic parameters, $\Delta \mathrm{H}, \Delta \mathrm{S}$ and $\Delta \mathrm{G}$ were computed using the relationships; $\Delta \mathrm{H}=\mathrm{E}-\mathrm{RT}, \Delta \mathrm{S}=\mathrm{R}[\ln (\mathrm{Ah} / \mathrm{kT})]$ and $\Delta \mathrm{G}=\Delta \mathrm{H}-\mathrm{T} \Delta \mathrm{S}$, where $\mathrm{k}$ is the Boltzmann's constant, $\mathrm{h}$ is the Planck's constant and T is the DTG peak temperature. The kinetic parameters are listed in Table-5 and Fig. 3.

From the results obtained, the following remarks can be pointed out: All decomposition stages show a best fit for $(\mathrm{n}=$ 1) indicating a first order decomposition in all cases. Taking the first and second decomposition stages as a criterion, the data show that activation energy $(\mathrm{E})$, enthalpy $(\Delta \mathrm{H})$, activation entropy $(\Delta S)$ and Gibbs free energy $(\Delta G)$, for metal complexes.

TABLE-5

KINETIC PARAMETERS DETERMINED USING THE COATS-REDFERN (CR)

\begin{tabular}{cccccccc}
\hline Compound & Stage & $\mathrm{E}\left(\mathrm{kJ} \mathrm{mol}^{-1}\right)$ & $\ln \mathrm{A}$ & $\Delta \mathrm{H}$ & $\Delta \mathrm{S}$ & $\Delta \mathrm{G}$ & $\mathrm{r}^{2}$ \\
\hline Ligand, $\mathrm{KL}$ & I & 55.98 & 9.50 & 53.30 & -0.167 & 112.12 & 0.998 \\
{$\left[\mathrm{Co}(\mathrm{L})_{2}\left(\mathrm{H}_{2} \mathrm{O}\right)_{2}\right]$} & I, II & $20.80,30.20$ & $2.23,3.21$ & $18.81,26.19$ & $-0.225,-0.222$ & $72.67,133.29$ & $0.998,0.998$ \\
{$\left[\mathrm{Ni}(\mathrm{L})_{2}\left(\mathrm{H}_{2} \mathrm{O}\right)_{2}\right]$} & I, II & $69.28,22.73$ & $12.23,0.439$ & $66.88,17.38$ & $-0.143,-0.248$ & $108.2,176.84$ & $0.997,0.998$ \\
{$\left[\mathrm{Cu}(\mathrm{L})_{2}\right]$} & I & 74.76 & 15.17 & 72.43 & -0.118 & 105.61 & 0.998 \\
\hline
\end{tabular}



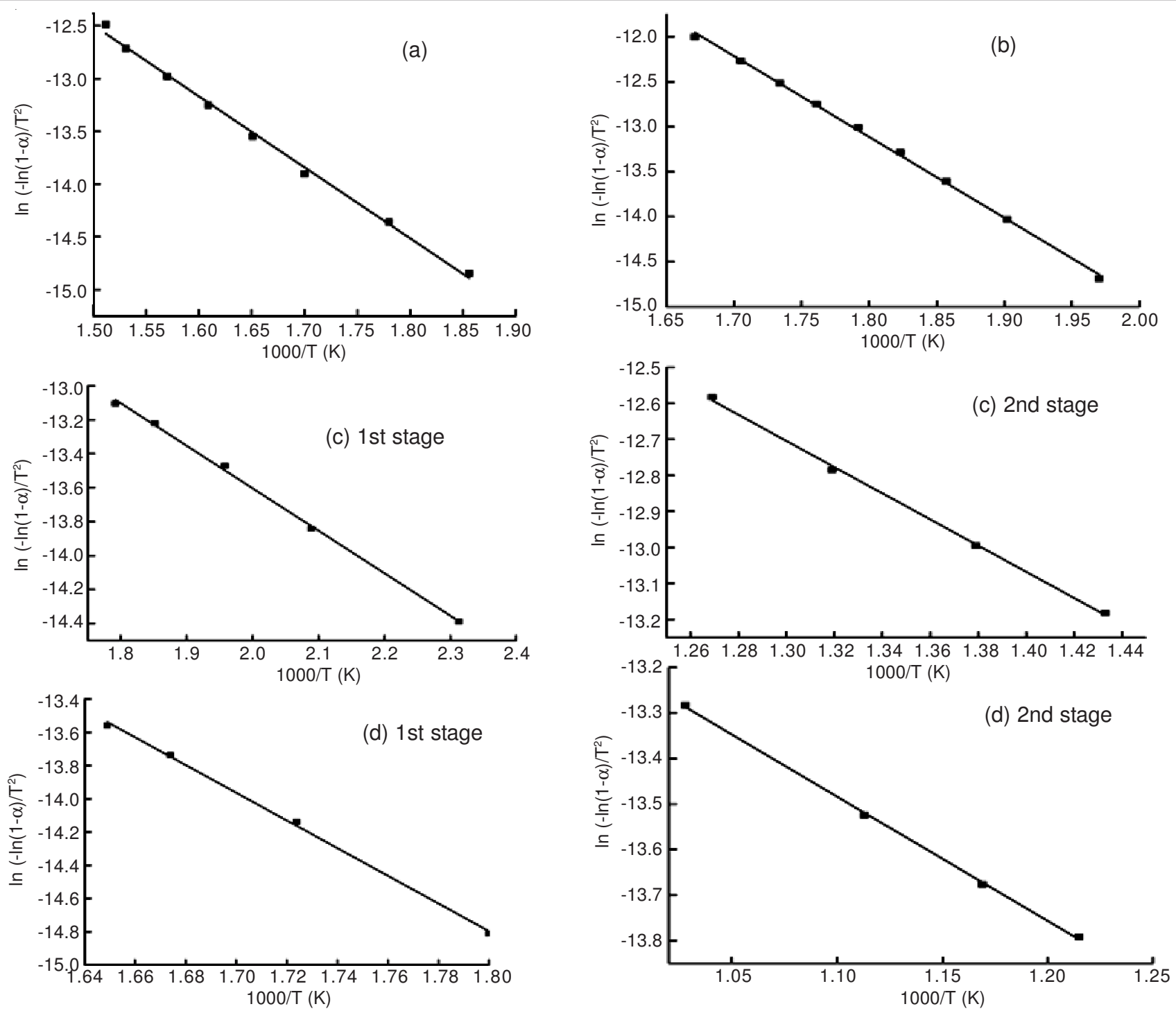

Fig. 3. Coats-Redfern (CR) plots for: (a) $\mathrm{KL}$ (b) $\mathrm{Cu}$ (II) (c) first stage and second stage of $\mathrm{Co}(\mathrm{II})$ and (d) first stage and second stage of $\mathrm{Ni(II)}$ complexes

All the complexes are higher values than those for ligand, this shows that the thermal stability for ligand is lower than that for metal complexes. The activation energy values increases on going from one decomposition stage to another for a $\mathrm{Co}$ (II) complex, indicating that the rate of decomposition decreases in the same order. This may be attributed to the structural rigidity of the remaining metal complex which requires more energy for its rearrangement before undergoing any compositional change. In case of $\mathrm{Ni}$ (II) complex the activation energy of second stage is lower than the first stage indicating that faster than first stage. The activation energy of $\mathrm{Co}(\mathrm{II}), \mathrm{Ni}(\mathrm{II})$ and $\mathrm{Cu}$ (II) complexes is expected to increase with decreasing in their radius ${ }^{25-27}$, the smaller size of $\mathrm{Cu}$ (II) permits a closer approach to the ligand as compared to $\mathrm{Co}(\mathrm{II}), \mathrm{Ni}$ (II). Hence activation energy value for the $\mathrm{Cu}$ (II) complex higher than that of others that is thermal stability of $\mathrm{Cu}$ (II) complex is higher than $\mathrm{Co}(\mathrm{II}), \mathrm{Ni}(\mathrm{II})$. The positive values of enthalpy $(\Delta \mathrm{H})$ mean that the decomposition processes are endothermic. The negative values of activation entropies $\Delta S$ indicate a more ordered activated complex than the reactants and/or the reactions are slow $^{28}$. The value of $\Delta \mathrm{G}$ increases significantly for the subsequently decomposition stages of a given complex. This is due to increasing values of $\mathrm{T} \Delta \mathrm{S}$ significantly from one stage to another which over rides the values of $\Delta H$. Increasing the values of $\Delta \mathrm{G}$ of a given complex as going from one decomposition step subsequently to another reflects that the rate of removal of the subsequent ligand will be lower than the precedent ligand ${ }^{29,30}$.

Electron-spray ionization mass spectra (ESI-MS): The positive and negative electron spray ionization mass spectra of the compounds were recorded in methanol (Table-6). The ESI-MS spectra of the compounds have differences of 1, 3 and 4 amu their calculated and observed mass fragmentations due to the isotopic nature of boron $\left({ }^{10} \mathrm{~B}\right.$ and $\left.{ }^{11} \mathrm{~B}\right)$, carbon $\left({ }^{12} \mathrm{C}\right.$ and ${ }^{13} \mathrm{C}$ ) and sulfur $\left({ }^{32} \mathrm{~S},{ }^{34} \mathrm{~S}\right)$. In some cases, the molecular ion peak was also associated with solvent, water molecules and some adduct ions from the mobile phase solution ${ }^{31}$. In positive ion ESI-mass spectrum of the ligand (Fig. 4), the molecular ion peak was observed at $\mathrm{m} / \mathrm{z} 384$, which is in agreement with the molecular weight (384) of the proposed structure and other fragmentation peaks at $m / z 317,288,229$ and 207 are ascribed to the cleavage of $\left[\mathrm{KBC}_{14} \mathrm{H}_{8} \mathrm{~N}_{2} \mathrm{~S}_{2}\right]^{+}, \quad\left[\mathrm{KBC}_{8} \mathrm{~N}_{2} \mathrm{~S}_{4}\right]^{+}$, $\left[\mathrm{KBC}_{8} \mathrm{H}_{6} \mathrm{NS}_{2}\right]^{+}$and $\left[\mathrm{C}_{10} \mathrm{H}_{3} \mathrm{NS}_{2}\right]^{+}$, respectively.

Positive ion ESI-MS spectra of metal complexes confirm the presence of dipositive mononuclear core structure. Positive 


\begin{tabular}{|c|c|c|c|}
\hline \multicolumn{4}{|c|}{$\begin{array}{c}\text { TABLE-6 } \\
\text { ESI-MS MASS SPECTRAL ANALYSIS OF THE } \\
\text { LIGAND AND ITS METAL COMPLEXES }\end{array}$} \\
\hline Compound & $\mathrm{m} / \mathrm{z}$ & Peak assignment & $\begin{array}{c}\text { Relative } \\
\text { abundance (\%) }\end{array}$ \\
\hline \multirow{5}{*}{ Ligand, KL } & 384 & {$\left[\mathrm{KBC}_{14} \mathrm{H}_{10} \mathrm{~N}_{2} \mathrm{~S}_{4}\right]^{+}$} & 12 \\
\hline & 317 & {$\left[\mathrm{KBC}_{14} \mathrm{H}_{8} \mathrm{~N}_{2} \mathrm{~S}_{2}\right]^{+}$} & 50 \\
\hline & 288 & {$\left[\mathrm{BC}_{8} \mathrm{H}_{8} \mathrm{ON}_{2} \mathrm{~S}_{4}\right]^{+}$} & 95 \\
\hline & 229 & {$\left[\mathrm{KBC}_{8} \mathrm{H}_{6} \mathrm{NS}_{2}\right]^{+}$} & 60 \\
\hline & 207 & {$\left[\mathrm{C}_{10} \mathrm{H}_{3} \mathrm{NS}_{2}\right]^{+}$} & 35 \\
\hline \multirow{5}{*}[\mathrm{Co}(\mathrm{L})_{2}(\mathrm{H}_{2}\mathrm{O})_{2}]{} & 816 & {$\left[\mathrm{M}+\mathrm{CH}_{3} \mathrm{OH}\right]^{+}$} & 19 \\
\hline & 787 & {$[\mathrm{M}+2]^{+}$} & 38 \\
\hline & 751 & {$\left[\mathrm{M}-2 \mathrm{H}_{2} \mathrm{O}\right]^{+}$} & 65 \\
\hline & 548 & {$\left[\mathrm{BC}_{21} \mathrm{H}_{18} \mathrm{~N}_{3} \mathrm{~S}_{6} \mathrm{O}_{2}\right]^{+}$} & 53 \\
\hline & 359 & {$\left[\mathrm{~B}_{2} \mathrm{C}_{14} \mathrm{H}_{12} \mathrm{~N}_{2} \mathrm{~S}_{4}\right]^{+}$} & 32 \\
\hline \multirow{3}{*}[\mathrm{Ni}(\mathrm{L})_{2}(\mathrm{H}_{2}\mathrm{O})_{2}]{} & 786 & {$[\mathrm{M}+2]^{+}$} & 45 \\
\hline & 747 & {$\left[\mathrm{~B}_{2} \mathrm{C}_{28} \mathrm{H}_{18} \mathrm{~N}_{4} \mathrm{~S}_{8} \mathrm{Ni}\right]^{+}$} & 19 \\
\hline & 337 & {$\left[\mathrm{BC}_{14} \mathrm{~N}_{2} \mathrm{~S}_{4}\right]^{+}$} & 33 \\
\hline \multirow{3}{*}[\mathrm{Cu}(\mathrm{L})_{2}]{} & 753 & {$[\mathrm{M}-1]^{+}$} & 76 \\
\hline & 524 & {$\left[\mathrm{~B}_{2} \mathrm{C}_{21} \mathrm{H}_{16} \mathrm{~N}_{3} \mathrm{~S}_{6}\right]+$} & 64 \\
\hline & 347 & {$\left[\mathrm{C}_{14} \mathrm{H}_{12} \mathrm{~N}_{2} \mathrm{~S}_{4}\right]+$} & 17 \\
\hline
\end{tabular}

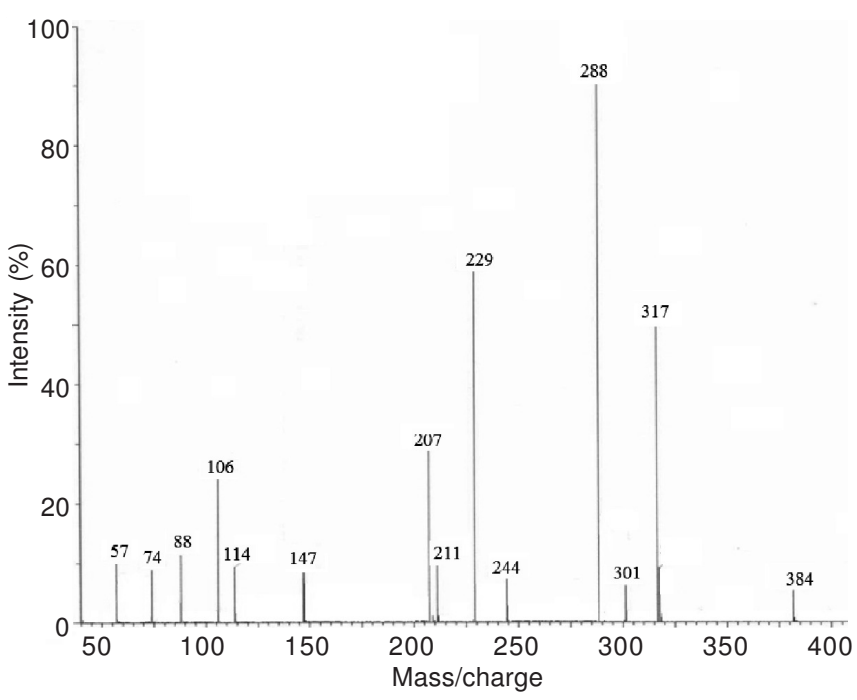

Fig. 4. ESI-Mass spectrum of ligand

ion spectra of the $\mathrm{Co}(\mathrm{II})$ and $\mathrm{Ni}(\mathrm{II})$ complexes show $[\mathrm{M}+2]^{+}$ peaks at $\mathrm{m} / z, 787$ and 786 , respectively, which supports the presence of coordinated water molecules. Copper(II) complex show $[\mathrm{M}-1]^{+}$peak at $m / z 753$. The most relevant fragmentations of ligand and its metal complexes with their assignments are shown in Table-6.

\section{Conclusion}

The results of this study clearly indicate that ligand is coordinated to metal ions via $>\mathrm{C}=\mathrm{S}$ group. The magnetic and electronic spectral studies of transition metal complexes suggest a square-planar geometry for the $\mathrm{Cu}$ (II) complex and octahedral configurations for $\mathrm{Ni}(\mathrm{II})$ and $\mathrm{Co}$ (II) ions. The stability of ligand and its metal complexes was explained and kinetic parameters of all thermal decomposition stages have been evaluated using Coats-Redfern method. These studies show that there is a relationship between the ionic radius of metal and thermal stability of their complexes.

\section{ACKNOWLEDGEMENTS}

One of the authors, Rizwan Wahab extended his appreciation to Deanship of Scientific Research at King Saud University for funding the work through the research group project No. RGPVPP-218.

\section{REFERENCES}

1. C. Janiak, T.G. Scharmann, J.C. Green, R.P.G. Perkin, M.J. Kolm, E.Riedel, W. Mickler, J. Elguero, R.M. Claramunt and D. Sanz, Chem. Eur. J., 2, 992 (1996)

2. H.V.R. Dias and W. Jin, Inorg. Chem., 35, 3687 (1996).

3. K. Bose, J. Haung, B.S. Haggerty, A.L. Rheingold, R.J. Salm and M.A. Walters, Inorg. Chem., 36, 4596 (1997).

4. L.F. Soares, D.C. Menezes, R.M. Silva, A.C. Doriguetto, J. Ellena, Y.P. Mascarenhas and E.E. Castellano, Polyhedron, 23, 205 (2004).

5. J.F. Ojo, P.A. Slavin, J. Reglinsky, M. Garner, M.D. Spicer, A.R. Kennedy and S.J. Teat, Inorg. Chim. Acta, 313, 15 (2001).

6. S.A. Nami, M. Alam, A. Husain and M. Parveen, Spectrochim. Acta A, 96, 729 (2012).

7. Effendy, G.G. Lobbia, C. Pettinari, C. Santini, B.W. Skelton and A.H. White, Inorg. Chim. Acta, 308, 65 (2000).

8. T. Ruman, Z. Ciunik and S. Wolowiec, Polyhedron, 23, 219 (2004).

9. R. Joshi, P. Kumar, S. Kumar and A.A. Hashmi, J. Coord. Chem. 61, 2437 (2008).

10. Z.H. Abd El-Wahab and M.R. El-Sarrag, Spectrochim. Acta A, 60, 271 (2004).

11. K.E. Erkkila, D.T. Odom and J.K. Barton, Chem. Rev., 99, 2777 (1999).

12. M.H. Baik, R.A. Friesner and S.J. Lippard, J. Am. Chem. Soc., 125, 14082 (2003).

13. B.H. Abdullah and Y.M. Salh, Oriental J. Chem., 26, 763 (2010).

14. S. Trofimenko, J. Am. Chem. Soc., 91, 2139 (1969).

15. A.K. Gupta and R.K. Poddar, Indian J. Chem., 39A, 1187 (2000).

16. C. Krafft, S. Brennecke, F. Ott, M. Backes, R. Salzer, J. Grunenberg, J.P. Ley, G.E. Krammer and B. Weber, Chem. Biodivers., 5, 1204 (2008).

17. S. Chandra and L.K. Gupta, Spectrochim. Acta A, 61, 1181 (2005).

18. B.N. Figgis, Introduction to Ligand Fields, Wiley Eastern Limited, p. 226 (1966).

19. A. Bajpai and S. Rai, J. Appl. Polym. Sci., 69, 751 (1998).

20. A.B.P. Lever, Inorganic Electronic Spectroscopy, Elsevier, Amsterdam (1984).

21. K.S. Siddiqi, A. Umar, S.A. Nami and S. Khan, J. Serb. Chem. Soc., 71, 1137 (2006).

22. P.R. Athappan and G. Rajagopal, Polyhedron, 15, 527 (1996).

23. M.S. Refat, A.M. El-Didamony and I. Grabchev, Spectrochim. Acta A, 67, 58 (2007).

24. A.W. Coats and J.P. Redfern, Nature, 201, 68 (1964).

25. G.S. Sodhi, Thermochim. Acta, 120, 107 (1987).

26. H.S. Sangari and G.S. Sodhi, Thermochim. Acta, 171, 49 (1990).

27. M. Lalia-Kantouri, G.A. Katsoulos, C.C. Hadjikostas and P. Kokorotsikos, J. Thermal Anal., 35, 2411 (1989).

28. A.A. Frost and R.G. Pearson, Kinetics and Mechanism, Wiley, New York (1961).

29. P.B. Maravalli and T.R. Goudar, Thermochim. Acta, 325, 35 (1999).

30. K.K.M. Yusuff and R. Sreekala, Thermochim. Acta, 159, 357 (1990).

31. M. Mann, Org. Mass Spectrom., 25, 575 (1990). 